\title{
Capacitative calcium entry in testosterone-induced intracellular calcium oscillations in myotubes
}

\author{
M Estrada ${ }^{1,2}$, A Espinosa ${ }^{1}$, C J Gibson ${ }^{2}$, P Uhlen $^{2}$ and \\ E Jaimovich ${ }^{1}$ \\ ${ }^{1}$ Centro de Estudios Moleculares de la Célula and Instituto de Ciencias Biomédicas, Facultad de Medicina, Universidad de Chile, Casilla 70005 , \\ Santiago 6530499, Chile \\ ${ }^{2}$ Departments of Pharmacology and Cellular and Molecular Physiology, Yale University School of Medicine, 333 Cedar Street, New Haven, \\ Connecticut 06520, USA \\ (Requests for offprints should be addressed to E Jaimovich; Email: ejaimovi@med.uchile.cl)
}

\begin{abstract}
$\mathrm{Ca}^{2+}$ oscillations are one of the most important signals within the cell. The mechanism for generation of $\mathrm{Ca}^{2+}$ oscillations is still not yet fully elucidated. We studied the role of capacitative $\mathrm{Ca}^{2+}$ entry (CCE) on intracellular $\mathrm{Ca}^{2+}$ oscillations induced by testosterone at the single-cell level in primary myotubes. Testosterone (100 nM) rapidly induced an intracellular $\mathrm{Ca}^{2+}$ rise, accompanied by $\mathrm{Ca}^{2+}$ oscillations in a majority of myotubes. Spectral analysis of the $\mathrm{Ca}^{2+}$ oscillations revealed a periodicity of $20 \cdot 3 \pm 1 \cdot 8 \mathrm{~s}$ (frequency of $49 \cdot 3 \pm 4 \cdot 4 \mathrm{mHz}$ ). In $\mathrm{Ca}^{2+}$-free medium, an increase in intracellular $\mathrm{Ca}^{2+}$ was still observed, but no oscillations. Neither nifedipine nor ryanodine affected the testosterone-induced $\mathrm{Ca}^{2+}$ response. This intracellular $\mathrm{Ca}^{2+}$ release was previously shown in myotubes to be dependent on inositol-1,4,5-trisphosphate $\left(\mathrm{IP}_{3}\right)$. Intracellular $\mathrm{Ca}^{2+}$ store depletion in $\mathrm{Ca}^{2+}$-free medium, using
\end{abstract}

a sarcoplasmic/endoplasmic reticulum calcium ATPasepump inhibitor, followed by re-addition of extracellular $\mathrm{Ca}^{2+}$, gave a fast rise in intracellular $\mathrm{Ca}^{2+}$, indicating that CCE was present in these myotubes. Application of either testosterone or albumin-bound testosterone induced $\mathrm{Ca}^{2+}$ release and led to CCE after re-addition of $\mathrm{Ca}^{2+}$ to $\mathrm{Ca}^{2+}$-free extracellular medium. The CCE blockers 2-aminoethyl diphenylborate and $\mathrm{La}^{3+}$, as well as perturbation of the cytoskeleton by cytochalasin $\mathrm{D}$, inhibited testosterone-induced $\mathrm{Ca}^{2+}$ oscillations and CCE. The steady increase in $\mathrm{Ca}^{2+}$ induced by testosterone was not, however, affected by either $\mathrm{La}^{3+}$ or cytochalasin $\mathrm{D}$. These results demonstrate testosterone-induced $\mathrm{Ca}^{2+}$ oscillations in myotubes, mediated by the interplay of $\mathrm{IP}_{3}$-sensitive $\mathrm{Ca}^{2+}$ stores and $\mathrm{Ca}^{2+}$ influx through CCE.

Journal of Endocrinology (2005) 184, 371-379

\section{Introduction}

Testosterone, an anabolic steroid hormone, produces both genomic (Powers \& Florini 1975, Mooradian et al. 1987) and non-genomic (Estrada et al. 2003) effects in skeletal muscle cells. The genomic effects involve interactions of testosterone with intracellular androgen receptor (Cato \& Perterziel 1998, Lee et al. 2003), whereas non-genomic effects are characterized by rapid second messenger participation. We have shown that in myotubes testosterone produces an intracellular $\mathrm{Ca}^{2+}$ increase with an oscillatory pattern. The $\mathrm{Ca}^{2+}$ increase elicited by androgens in myotubes is due to $\mathrm{Ca}^{2+}$ released from intracellular stores, as the response is still produced in $\mathrm{Ca}^{2+}$-free medium. It involves the formation of inositol1,4,5-trisphosphate $\left(\mathrm{IP}_{3}\right)$ through phospholipase $\mathrm{C}$ activation because inhibitors of the $\mathrm{IP}_{3}$-mediated pathway almost completely inhibit the testosterone-induced $\mathrm{Ca}^{2+}$ increase (Estrada et al. 2000, 2003). The rapid effects of androgens are initiated at the plasma membrane, as shown by testosterone covalently bound to albumin (T-BSA), which does not cross the membrane yet still produces an intracellular $\mathrm{Ca}^{2+}$ increase which involves a receptor coupled to a pertussis toxin-sensitive $G$ protein (Lieberherr \& Grosse 1994, Benten et al. 1999, Estrada et al. 2003, Zagar et al. 2004). Thus, androgen-evoked $\mathrm{Ca}^{2+}$ oscillations in myotubes may involve concerted actions between events at the plasma membrane and internal stores, $\mathrm{Ca}^{2+}$ release from the sarcoplasmic reticulum being a key event for this mechanism. It has been proposed that different intracellular $\mathrm{Ca}^{2+}$ oscillatory patterns may preferentially activate or inactivate separate $\mathrm{Ca}^{2+}-$ dependent processes related to regulation of gene expression (Li et al. 1998, Estrada et al. 2000, Powell et al. 2001). In myotubes, this could lead to, for example, differential activation or repression of genes due to $\mathrm{Ca}^{2+}$ signaling 
(Cato \& Peterziel 1998, Jaimovich et al. 2000, Powell et al. 2001). In several cell types, agonist stimulation leads to a complex intracellular $\mathrm{Ca}^{2+}$ signal consisting of a peak increase due to the release of $\mathrm{Ca}^{2+}$ from the $\mathrm{IP}_{3}$-sensitive endoplasmic reticulum followed by a sustained phase due to the entry of $\mathrm{Ca}^{2+}$ from the external medium through store-operated channels (SOCs) (Putney et al. 2001, Venkatachalam et al. 2002). This secondary influx of $\mathrm{Ca}^{2+}$ is stimulated by the depletion of intracellular $\mathrm{Ca}^{2+}$ stores and has been called capacitative $\mathrm{Ca}^{2+}$ entry (CCE). Diverse hypotheses to explain the initiation of CCE have been suggested, including a diffusible factor, exocytosis of $\mathrm{Ca}^{2+}$-release activated $\mathrm{Ca}^{2+}$ channel and a structural link between the plasma membrane and intracellular stores. This last hypothesis involves a conformational coupling between $\mathrm{IP}_{3}$ receptors $\left(\mathrm{IP}_{3} \mathrm{R}\right)$ and $\mathrm{Ca}^{2+}$ channels in the plasma membrane (Venkatachalam et al. 2002). The existence of CCE in skeletal muscle cells has been demonstrated (Kurebayashi \& Ogawa 2001, Islam et al. 2002), and conformational coupling between the plasma membrane and either ryanodine receptors (Islam et al. 2002) or $\mathrm{IP}_{3} \mathrm{Rs}$ (Kiselyov et al. 1998, Launikonis et al. 2003) has been postulated. In both models, it has been suggested that regulation of $\mathrm{Ca}^{2+}$ depletion from intracellular stores and the subsequent $\mathrm{Ca}^{2+}$ influx from the extracellular space through SOCs, requires an integral link between the plasma membrane and internal stores.

Actin microfilaments represent the main cytoskeletal component of differentiated skeletal muscle cells. It has been demonstrated that disruption of the actin cytoskeleton in some cell types can affect the link between plasma membrane $\mathrm{Ca}^{2+}$ channels and intracellular $\mathrm{Ca}^{2+}$ stores (Pedrosa-Ribeiro et al. 1997) as well as affecting intracellular $\mathrm{Ca}^{2+}$ oscillations (Sergeeva et al. 2000). This effect depends on the cell type studied, as some reports indicate that disruption of actin filaments modifies the initial $\mathrm{Ca}^{2+}$ increases without affecting CCE (PedrosaRibeiro et al. 1997), whereas others have shown that treatment with the fungal toxin cytochalasin D modifies both the $\mathrm{Ca}^{2+}$ increase in response to thapsigargin as well as subsequent CCE (Sergeeva et al. 2000). In this work we show that testosterone induces CCE in myotubes and that extracellular $\mathrm{Ca}^{2+}$ influx participates in testosteroneinduced intracellular $\mathrm{Ca}^{2+}$ oscillations.

\section{Material and Methods}

\section{Chemical reagents}

Testosterone (4-androsten-17 $\beta$-ol-3-one), T-BSA (testosterone-3-(o-carboxymethyl)oxime:BSA), thapsigargin, nifedipine and cytochalasin $\mathrm{D}$ were purchased from Sigma. 2-Aminoethyl diphenylborate (2-APB) was obtained from Aldrich (St Louis, MO, USA). Fluo-3 acetoxymethylester (Fluo-3 AM) was purchased from Molecular Probes (Eugene, OR, USA). Other reagents were of analytical grade.

\section{Cell culture}

Rats were bred in the Animal Breeding facility of the Faculty of Medicine, University of Chile. We performed all studies with the approval of the institutional bioethical committee. Rat myotubes were cultured as reported previously (Estrada et al. 2000, Jaimovich et al. 2000). Briefly, myoblasts were obtained from neonatal rat hind limbs. The tissue was mechanically dispersed and then treated with $10 \%(\mathrm{w} / \mathrm{v})$ collagenase for $15 \mathrm{~min}$ at $37^{\circ} \mathrm{C}$ under mild agitation. The suspension was filtered through a Nytex (Sartorius, Goettingen, Germany) membrane and spun down at low speed. Pre-plating was used to partially eliminate fibroblasts; cells were then plated onto round coverslips at a density of $\sim 3.5 \times 10^{5}$ per dish. The culture medium was DMEM/F-12 without phenol red, 10\% bovine serum, $2 \cdot 5 \%$ fetal calf serum, $100 \mathrm{mg} / 1$ penicillin, $50 \mathrm{mg} / 1$ streptomycin and $2.5 \mathrm{mg} / 1$ amphotericin B. To eliminate remaining fibroblasts, $10 \mu \mathrm{M}$ cytosine arabinoside was added on the third day of culture for $24 \mathrm{~h}$. The medium was then replaced with serum-free medium. Myotubes with an estimated purity of more than 90\% were visible after the fifth day of culture. Unless otherwise indicated, we used 6- to 8-day-old cultures exhibiting a fairly homogeneous population of myotubes with central nuclei, measuring 200-300 $\mu \mathrm{m}$ long and 20-40 $\mu \mathrm{m}$ wide.

\section{Intracellular $\mathrm{Ca}^{2+}$}

For intracellular $\mathrm{Ca}^{2+}$ measurements at the single-cell level, myoblasts were cultured on glass coverslips to $80 \%$ confluence and then differentiated into myotubes by withdrawal of serum. $\mathrm{Ca}^{2+}$ images were obtained from myotubes loaded with the fluorescent $\mathrm{Ca}^{2+}$ dye Fluo-3 AM using an epifluorescence microscope (T041; Olympus Corp., New Hyde Park, NY, USA) equipped with a cooled CCD camera and image acquisition system (MCD 600; Spectra Source Instruments, Westlake Village, CA, USA). Myotubes were washed three times with Krebs buffer $(145 \mathrm{mM} \mathrm{NaCl}, 5 \mathrm{mM} \mathrm{KCl}, 2.6 \mathrm{mM} \mathrm{CaCl}, 1 \mathrm{mM}$ $\mathrm{MgCl}_{2}, 10 \mathrm{mM}$ Hepes-Na, $5.6 \mathrm{mM}$ glucose, $\left.\mathrm{pH} 7 \cdot 4\right)$ to remove serum, and loaded with $5 \cdot 4 \mu \mathrm{M}$ Fluo-3 AM (coming from a stock in pluronic acid-dimethylsulfoxide $20 \%$ ) for $30 \mathrm{~min}$ at room temperature. After loading, myotubes were washed with Krebs buffer for $10 \mathrm{~min}$ to allow the de-esterification of the dye, and used within $2 \mathrm{~h}$. The coverslips were mounted in a $1 \mathrm{ml}$ capacity plastic chamber and placed on the microscope for fluorescence measurements. Fluorescence images were collected every $1 \cdot 0-2 \cdot 0 \mathrm{~s}$ and analyzed frame by frame with the data acquisition program of the equipment (MCD 600; Spectra Source). A PlanApo $40 \times($ NA 1.4) objective lens was used. In most of the acquisitions, the image dimensions were $512 \times 120$ pixels. Inhibitors were added during the dye incubation; times and concentrations are indicated in the results section. To assess the role of the actin cytoskeleton 
on the intracellular $\mathrm{Ca}^{2+}$ response, cytochalasin $\mathrm{D}$ was added $20 \mathrm{~min}$ or $1 \mathrm{~h}$ before hormone stimulation. Intracellular $\mathrm{Ca}^{2+}$ was expressed as a percentage of fluorescence intensity relative to basal fluorescence (a value stable for at least $5 \mathrm{~min}$ in resting conditions). The increase in fluorescence intensity of Fluo-3 AM is proportional to the rise in intracellular $\mathrm{Ca}^{2+}$ (Minta et al. 1986). Each experiment involved a single independent cell and whole cell fluorescence was acquired. A given cell was considered to oscillate when oscillations were evident in the whole cell record.

\section{Digital image processing}

Elimination of out-of-focus fluorescence was performed by software. Both the 'no-neighbors' deconvolution algorithm and Castleman's point spread function theoretical model were used. Complementary to restoration methods, a procedure was created to section the images. To segment an image, an initial contour can be entered manually, and a recursive algorithm that adapts automatically to the region of interest (adaptable contour) can be applied (Estrada et al. 2000). To quantify fluorescence, the summed pixel intensity was calculated for the section delimited by a contour. As a way of increasing the efficiency of these data manipulations, action sequences were generated. To avoid possible interference in the fluorescence by changes in volume after exposure to steroids, the area of a fluorescent cell was determined by image analysis using an adaptive contour and then creating a binary mask, which was compared with a bright-field image.

\section{Power spectrum analysis}

We used an algorithm written in MATLAB to perform power spectrum analysis. The power spectrum of a signal is the squared Fourier transform, and describes the contribution to that signal by each of its sine wave components. The oscillating section from a single cell measurement was filtered, centered and trend corrected by computing the Gauss least-square approximation. To derive the discrete Fourier transform, a fast Fourier transform was used. This calculation produced a spectrum where the peaks correspond to the different frequencies present in the original data. The most dominant peak was determined by comparing the relative power of the peaks in the spectrum. The relative power was determined by calculating the area between the two extremes closest to the peak and dividing by the total area of the power spectrum, as described (Aizman et al. 2001, Miyakawa-Naito et al. 2003).

\section{Statistics}

Differences between basal and post-stimulated points were determined using a paired Student's $t$-test. $P<0 \cdot 05$ was considered statistically significant.
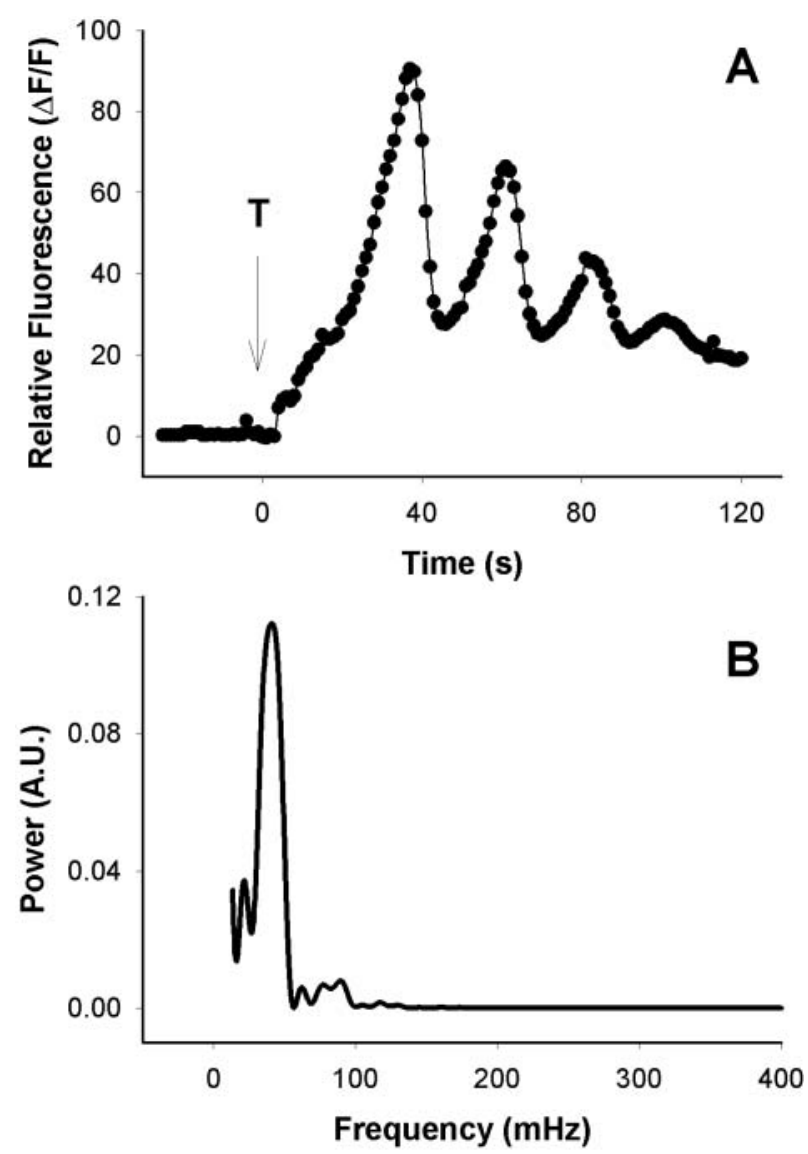

Figure 1 Intracellular $\mathrm{Ca}^{2+}$ oscillations induced by testosterone in myotubes. Testosterone $(100 \mathrm{nM})$ induced a rapid intracellular $\mathrm{Ca}^{2+}$ increase with an oscillatory pattern in Fluo-3 AM-loaded myotubes. (A) A representative single-cell trace of myotube response in a $\mathrm{Ca}^{2+}$-containing medium, and (B) the corresponding power spectrum analysis of the oscillations from the same cell as in (A). In this particular experiment, the analysis reveals a relatively constant oscillation frequency of $41 \cdot 1 \mathrm{mHz}$, equivalent to a period of $24.3 \mathrm{~s}$. The arrow indicates the time of testosterone (T) addition. A.U., arbitrary units.

\section{Results}

We have previously demonstrated that testosterone induces intracellular $\mathrm{Ca}^{2+}$ increases independently of the intracellular androgen receptor (Estrada et al. 2000, 2003). From those studies, a concentration of $100 \mathrm{nM}$ testosterone was determined to produce highly reproducible $\mathrm{Ca}^{2+}$ responses in myotubes and so was used for the following set of experiments. The effects of testosterone $(100 \mathrm{nM})$ on intracellular $\mathrm{Ca}^{2+}$ in myotubes are shown in Fig. 1A. From a total of 176 cells in 32 independent primary cultures, 134 cells responded to testosterone with a $\mathrm{Ca}^{2+}$ increase. A majority of cells challenged with testosterone exhibited $\mathrm{Ca}^{2+}$ oscillations (76\%; $n=101$ of 134 cells). This oscillatory response was initiated by a rapid peak in the 
intracellular $\mathrm{Ca}^{2+}$ accompanied by oscillations. When the cells were exposed to testosterone, $\mathrm{Ca}^{2+}$ rapidly increased (34 \pm 12 s range $10-49$ s) after hormone addition. This $\mathrm{Ca}^{2+}$ rise was maintained for 1-2 min while the oscillatory pattern was observed. Once the intracellular $\mathrm{Ca}^{2+}$ concentration returned to the basal level, oscillations could no longer be detected. Responding cells that did not oscillate exhibited a similar rise in intracellular $\mathrm{Ca}^{2+} \cdot \mathrm{Ca}^{2+}$ oscillations are characterized by frequency and amplitude. These two features have previously been shown to be of critical importance for the physiological response activated by $\mathrm{Ca}^{2+}$ oscillations (Dolmetsch et al. 1998, Li et al. 1998). To examine the regularity of testosterone-induced $\mathrm{Ca}^{2+}$ oscillations we performed a power spectrum analysis (Fig. 1B). By applying this method we could determine similarities among all single-cell recordings. The power spectrum of an oscillatory signal describes the contribution to that signal of different sine wave components (Aizman et al. 2001). This analysis thus allows the most dominant frequency contribution to be determined from a complex signal. Moreover, irregular and random contributions to the signal are excluded by this approach. Spectral analysis of $\mathrm{Ca}^{2+}$ oscillations induced by testosterone generated a signal which could be described with an average frequency of $49 \cdot 3 \pm 4 \cdot 4 \mathrm{mHz}$, which corresponds to an average periodicity of $20 \cdot 3 \pm 1 \cdot 8 \mathrm{~s}$.

In order to determine the source(s) of $\mathrm{Ca}^{2+}$ implicated in the testosterone-induced $\mathrm{Ca}^{2+}$ increase, myotubes were incubated in $\mathrm{Ca}^{2+}$-free medium (1 mM EGTA) prior to androgen stimulation. Under this condition, a sustained $\mathrm{Ca}^{2+}$ increase was still seen for both testosterone-treated (Fig. 2A; $n=32$ of 41 cells; seven independent cultures) and T-BSA-treated cells (Fig. 2A, inset; $n=12$ of 14 cells; five independent cultures); however, intracellular $\mathrm{Ca}^{2+}$ oscillations were completely abolished. These results suggest that the $\mathrm{Ca}^{2+}$ response elicited by testosterone consists of at least two components: an intracellular release contributing to the rise in $\mathrm{Ca}^{2+}$, and a $\mathrm{Ca}^{2+}$ influx from the extracellular medium, which is required for oscillations. We have previously shown that $\mathrm{Ca}^{2+}$ signals evoked by testosterone were dependent on both the generation of $\mathrm{IP}_{3}$ and on the activity of $\mathrm{IP}_{3} \mathrm{Rs}$ (Estrada et al. 2000, 2003). We now tested whether $\mathrm{Ca}^{2+}$ signals were also related to ryanodine and dihydropyridine receptors. Oscillations were not due to activation of L-type voltage-operated $\mathrm{Ca}^{2+}$ channels, as nifedipine $(10 \mu \mathrm{M})$ did not modify the $\mathrm{Ca}^{2+}$ oscillations induced by testosterone (Fig. $2 \mathrm{~B} ; n=12$ of 16 cells; three independent cultures). Similarly, pretreatment of myotubes with $20 \mu \mathrm{M}$ ryanodine, a concentration known to block $\mathrm{Ca}^{2+}$ release through ryanodine receptors (Jaimovich et al. 2000), did not modify the hormone-mediated intracellular $\mathrm{Ca}^{2+}$ oscillations (Fig. 2B; $n=10$ of 14 cells; three independent cultures), suggesting that $\mathrm{Ca}^{2+}$ mobilization did not involve ryanodine receptors.

Treatment of myotubes with thapsigargin $(1 \mu \mathrm{M})$, an inhibitor of the sarcoplasmic reticulum $\mathrm{Ca}^{2+}$-ATPase

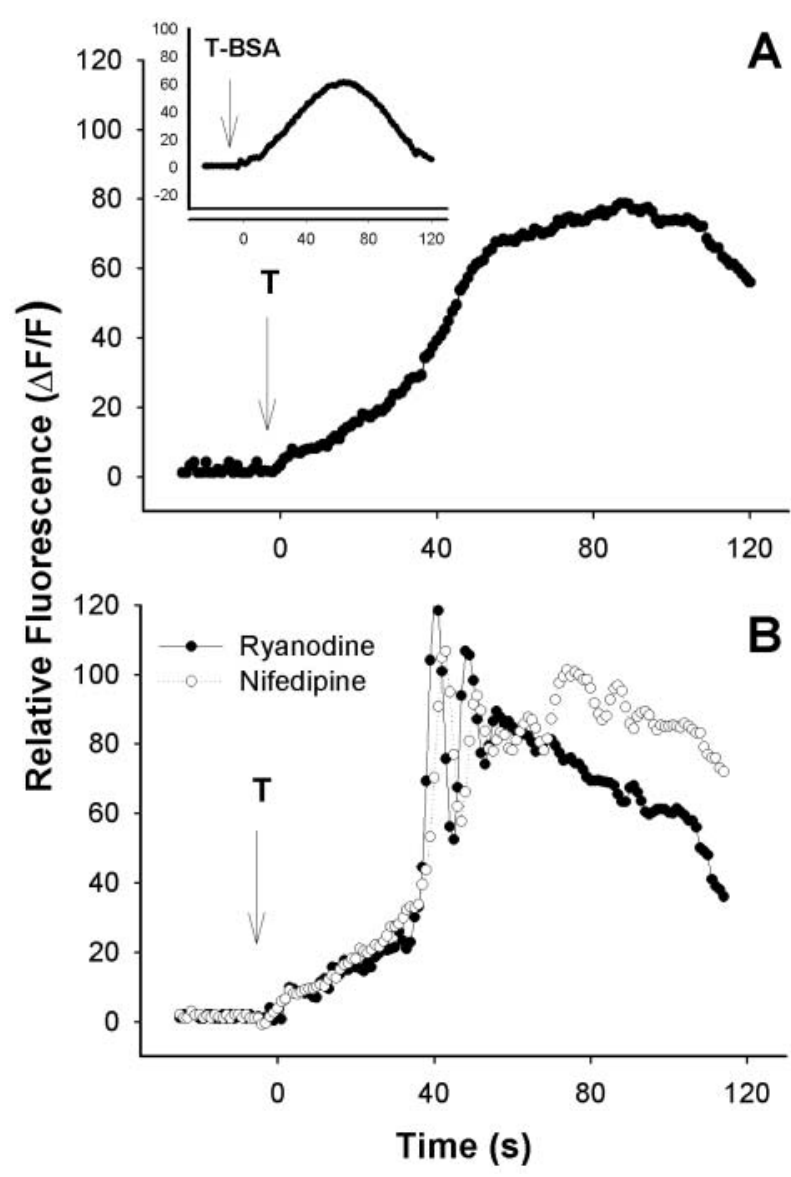

Figure 2 Effect of $\mathrm{Ca}^{2+}$-free medium, nifedipine and ryanodine on testosterone-induced $\mathrm{Ca}^{2+}$ oscillations. (A) Pre-incubation of Fluo-3 AM-loaded myotubes in $\mathrm{Ca}^{2+}$-free medium (1 mM EGTA) for 5 min did not affect the fluorescence rise after stimulation with $100 \mathrm{nM}$ testosterone or T-BSA (inset), but did inhibit subsequent $\mathrm{Ca}^{2+}$ oscillations. (B) Representative traces of experiments in the presence of $\mathrm{Ca}^{2+}$ channels inhibitors. Neither nifedipine nor ryanodine modified the testosterone-induced $\mathrm{Ca}^{2+}$ oscillations in a $\mathrm{Ca}^{2+}$-containing medium.

pump, in $\mathrm{Ca}^{2+}$-free medium showed an intracellular $\mathrm{Ca}^{2+}$ increase due to $\mathrm{Ca}^{2+}$ release from intracellular stores (Fig. $3 \mathrm{~A} ; n=20$ of 20 cells; four independent cultures). A slow $\mathrm{Ca}^{2+}$ increase followed by a decrease back to the basal level characterized this response. The intracellular $\mathrm{Ca}^{2+}$ level of myotubes not treated with thapsigargin was unchanged after the removal of $\mathrm{Ca}^{2+}$ in the extracellular medium ( $n=12$ of 12 cells; three independent cultures, data not shown). Re-addition of $\mathrm{Ca}^{2+}(2 \mathrm{mM})$ to the extracellular medium produced a fast intracellular $\mathrm{Ca}^{2+}$ increase in thapsigargin-treated cells, suggesting that depletion of intracellular stores promoted $\mathrm{Ca}^{2+}$ entry from the extracellular medium (Fig. 3A).

These results suggest that activation of CCE occurs by emptying the $\mathrm{IP}_{3}$-sensitive $\mathrm{Ca}^{2+}$ stores according to 


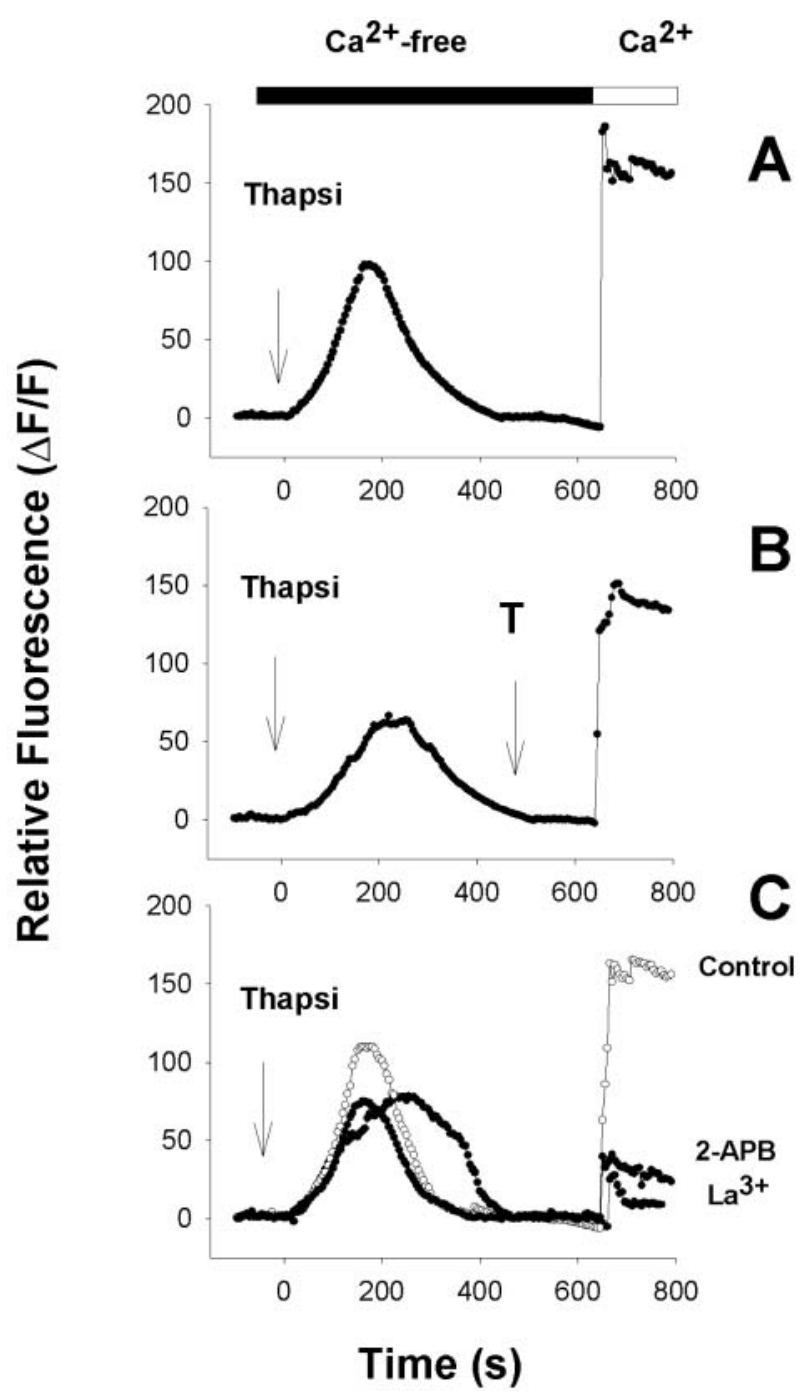

Figure 3 Thapsigargin (Thapsi) activation of SOCs in myotubes. Cells loaded with Fluo-3 AM were incubated in $\mathrm{Ca}^{2+}$-free medium and treated with $1 \mu \mathrm{M}$ thapsigargin. (A) In the absence of extracellular $\mathrm{Ca}^{2+}$, thapsigargin induced a transient increase in intracellular $\mathrm{Ca}^{2+}$. Subsequent addition of $\mathrm{Ca}^{2+}(2 \mathrm{mM})$ to the extracellular medium resulted in a large intracellular $\mathrm{Ca}^{2+}$ increase suggesting initiation of CCE. (B) Testosterone did not produce any change in the fluorescence in myotubes after depletion of thapsigargin-sensitive stores. (C) Pre-incubation with $\mathrm{La}^{3+}$ or 2-APB did not affect the thapsigargin-induced $\mathrm{Ca}^{2+}$ transient, but did reduce the subsequent intracellular $\mathrm{Ca}^{2+}$ rise after addition of $2 \mathrm{mM} \mathrm{Ca}^{2+}$ to the extracellular medium, further supporting the suggestion of thapsigargin-sensitive CCE.

a previously demonstrated testosterone-induced $\mathrm{IP}_{3}$ activation pathway (Estrada et al. 2000, 2003).

Pre-treatment of myotubes with thapsigargin blocked the $\mathrm{Ca}^{2+}$ signal induced by testosterone, indicating that the $\mathrm{Ca}^{2+}$ increase produced by this hormone involves, at least in part, thapsigargin-sensitive intracellular $\mathrm{Ca}^{2+}$ stores (Fig. 3B; $n=8$ of 8 cells; three independent cultures). Both

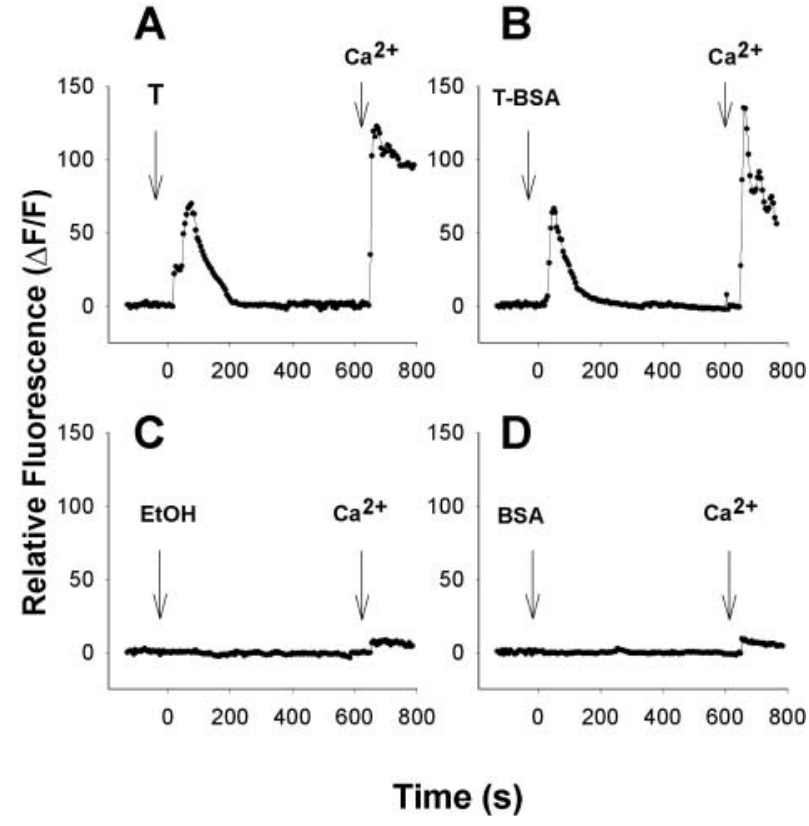

Figure 4 Testosterone- and T-BSA-induced activation of CCE in myotubes. Cells bathed in $\mathrm{Ca}^{2+}$-free extracellular medium were stimulated with testosterone (A) or T-BSA (B). Both initiated a transient intracellular $\mathrm{Ca}^{2+}$ increase that was not seen when cells were stimulated with vehicle (C) or BSA alone (D). Upon re-addition of extracellular $\mathrm{Ca}^{2+}(2 \mathrm{mM})$, hormone-stimulated cells exhibited a sustained intracellular $\mathrm{Ca}^{2+}$ increase not present in control-stimulated cells, suggesting a mechanism of hormone-induced CCE.

$\mathrm{La}^{3+}$, a non-specific $\mathrm{Ca}^{2+}$ channel blocker, and 2-APB, were reported to inhibit CCE in several cellular models (Jaimovich et al. 2000, Bootman et al. 2002, Collet \& Ma 2004). In accord with these reports, $\mathrm{La}^{3+}$ and 2-APB did not inhibit thapsigargin-induced $\mathrm{Ca}^{2+}$ release from intracellular stores (Fig. 3C). The thapsigargin-evoked $\mathrm{Ca}^{2+}$ entry in myotubes was, however, significantly reduced by $1 \mu \mathrm{M}$ to $1 \mathrm{mM} \mathrm{La}^{3+}(80 \%, P<0 \cdot 05 ; n=16$ of 16 cells; five independent cultures) or $50 \mu \mathrm{M} 2$-APB $(76 \%, P<0 \cdot 05$; $n=18$ of 18 cells; six independent cultures) (Fig. 3C).

To determine whether CCE participates in the response to testosterone, experiments similar to those with thapsigargin were performed. Figure 4A shows a testosterone-induced intracellular $\mathrm{Ca}^{2+}$ increase in a myotube incubated in $\mathrm{Ca}^{2+}$-free medium. Re-addition of $2 \mathrm{mM} \mathrm{Ca}^{2+}$ to the extracellular medium produced a rapid and sustained $\mathrm{Ca}^{2+}$ entry (Fig. 4A; $n=21$ of 21 cells; four independent cultures). These results suggest that activation of CCE occurs by emptying the $\mathrm{IP}_{3}$-sensitive $\mathrm{Ca}^{2+}$ stores according to a testosterone-induced $\mathrm{IP}_{3}$ activation pathway previously demonstrated (Estrada et al. 2000, 2003). The vehicle, ethanol $(<0 \cdot 01 \%)$, did not induce a $\mathrm{Ca}^{2+}$ increase and re-addition of extracellular $\mathrm{Ca}^{2+}$ $(2 \mathrm{mM})$ produced only a slight increase in intracellular $\mathrm{Ca}^{2+}$ (Fig. $4 \mathrm{C} ; \Delta \mathrm{F} / \mathrm{F}=5 \cdot 2 \pm 3 \cdot 1 ; n=6$ of 6 cells; two 
independent cultures). To verify that the testosteroneinduced $\mathrm{Ca}^{2+}$ release was not due to activation of the intracellular androgen receptor, we performed experiments using plasma-membrane-impermeable T-BSA. Under similar conditions, T-BSA induced CCE (Fig. 4B; $n=12$ of 12 cells; four independent cultures) but albumin by itself did not cause any intracellular $\mathrm{Ca}^{2+}$ increase (Fig. $4 \mathrm{D} ; n=6$ of 6 cells; two independent cultures). In these myotubes the $\mathrm{Ca}^{2+}$ re-addition protocol produced a relative fluorescence increase of $6 \cdot 1 \pm 1 \cdot 1$. This small rise in the baseline $\mathrm{Ca}^{2+}$ signal after re-addition of extracellular $\mathrm{Ca}^{2+}$ in vehicle-treated cells could be expected, in $\mathrm{Ca}^{2+}$ free conditions, through cytosolic $\mathrm{Ca}^{2+}$ leak pathways more than through activation of a CCE pathway. The relative change of fluorescence intensity was at least one order of magnitude greater when cells were exposed to testosterone vs vehicle, which suggests that $\mathrm{Ca}^{2+}$ entry is activated by testosterone application.

To determine whether CCE participates in the generation of testosterone-induced $\mathrm{Ca}^{2+}$ oscillations, experiments using CCE inhibitors were performed. As shown in Fig. 5A, application of $\mathrm{La}^{3+}$ blocked testosterone-evoked $\mathrm{Ca}^{2+}$ oscillations. Pre-incubation of myotubes with $\mathrm{La}^{3+}$ before the addition of testosterone in $\mathrm{Ca}^{2+}$-free medium did not cause a detectable inhibition of testosteroneinduced $\mathrm{Ca}^{2+}$ release from intracellular stores, but completely inhibited $\mathrm{Ca}^{2+}$ oscillations (Fig. 5B; $n=11$ of 11 cells; four independent cultures). Moreover, Fig. 5B shows that $\mathrm{La}^{3+}$ and 2-APB inhibited steroid-induced $\mathrm{Ca}^{2+}$ influx in $\mathrm{Ca}^{2+}$ re-addition experiments by $80 \%$ (range $68-95 \%, P<0 \cdot 05 ; n=18$ of 18 cells; four independent cultures) and by $73 \%$ (range $65-82 \%, P<0 \cdot 05 ; n=25$ of 25 cells; seven independent cultures) respectively, similar to effects of these agents on thapsigargin-induced $\mathrm{Ca}^{2+}$ influx (Fig. 3C). These results suggest that CCE participates in testosterone-induced $\mathrm{Ca}^{2+}$ oscillations in rat skeletal myotubes.

To assess the role of the actin cytoskeleton on intracellular $\mathrm{Ca}^{2+}$ increases induced by testosterone, cytochalasin $\mathrm{D}$, an actin-depolymerizing agent, was applied to disrupt the cytoskeletal structure of actin filaments. Preincubation of myotubes with $10 \mu \mathrm{M}$ cytochalasin $\mathrm{D}$ for $20 \mathrm{~min}$ prior to testosterone application reduced the number of oscillating cells (30\% vs $76 \%$ of testosteroneresponsive cells; $n=21$ cells from four independent cultures), whereas pre-incubation for $1 \mathrm{~h}$ blocked $\mathrm{Ca}^{2+}$ oscillations (Fig. 6A; $n=18$ of 18 cells; three independent cultures). The testosterone-induced intracellular $\mathrm{Ca}^{2+}$ increase persisted, although reduced in magnitude $(29 \%$ with respect to control (Fig. 2A), $P<0 \cdot 05$; range 15-38; $n=20$ of 20 cells; three independent cultures). The role of the actin cytoskeleton on CCE mediated by testosterone was also evaluated through re-addition of extracellular $\mathrm{Ca}^{2+}$. Figure $6 \mathrm{~B}$ shows that incubation of myotubes with cytochalasin $\mathrm{D}$ for $1 \mathrm{~h}$ reduced the testosterone-stimulated $\mathrm{Ca}^{2+}$ rise in $\mathrm{Ca}^{2+}$-free medium, and inhibited

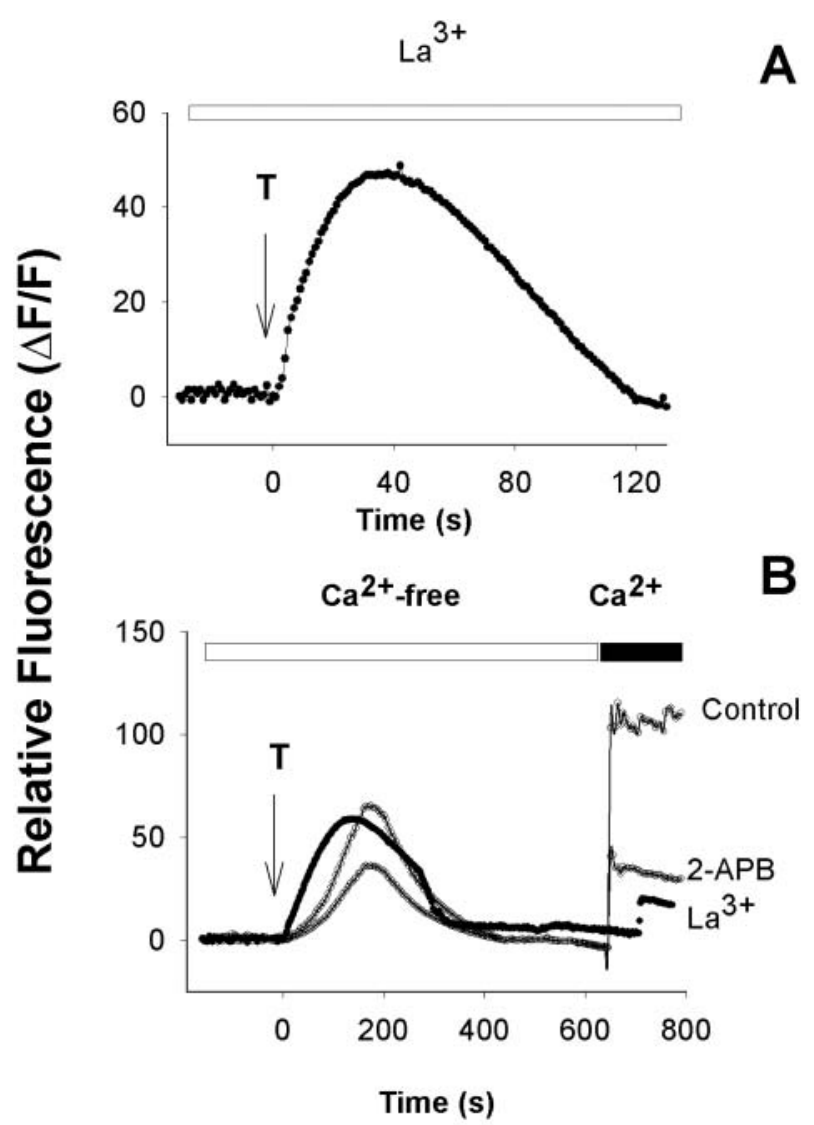

Figure 5 Effect of $\mathrm{La}^{3+}$ and 2-APB on testosterone-induced $\mathrm{Ca}^{2+}$ signals. (A) Testosterone was added in the absence of external $\mathrm{Ca}^{2+} \cdot \mathrm{La}^{3+}$ inhibited the $\mathrm{Ca}^{2+}$ oscillations but not the initial $\mathrm{Ca}^{2+}$ increase induced by testosterone. (B) Inhibitors of CCE were added 10 min before testosterone stimulation. Upon $\mathrm{Ca}^{2+}$ re-addition, CCE was reduced by either $\mathrm{La}^{3+}$ or 2-APB. These results suggest that testosterone activates CCE in a similar manner to thapsigargin (Fig. 3C), and that this CCE is required for testosterone-induced intracellular $\mathrm{Ca}^{2+}$ oscillations. The arrow indicates the time of addition of testosterone (T).

testosterone-induced CCE by $43 \%$ (range 23-56\%, $P<0 \cdot 05 ; n=10$ of 10 cells; two independent cultures) with respect to the control condition. These results imply that an intact actin cytoskeleton is necessary for myotubes to generate $\mathrm{Ca}^{2+}$ oscillations.

\section{Discussion}

Androgens can produce rapid effects in myotubes through mechanisms other than a genomic response; however, these mechanisms are not yet fully understood. Previously, we demonstrated that a key step in the rapid testosterone response of myotubes is an increase in intracellular $\mathrm{Ca}^{2+}$, observable as $\mathrm{Ca}^{2+}$ oscillations and propagated $\mathrm{Ca}^{2+}$ waves (Estrada et al. 2000, 2003). In this study, we show 

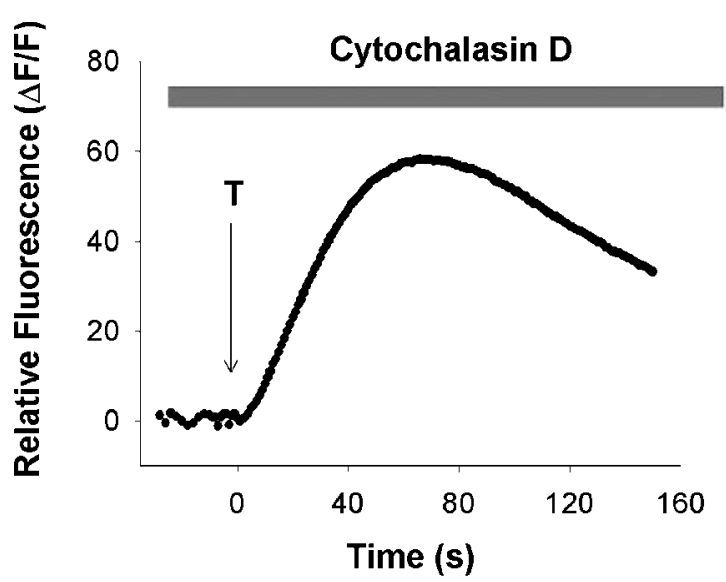

\section{A}

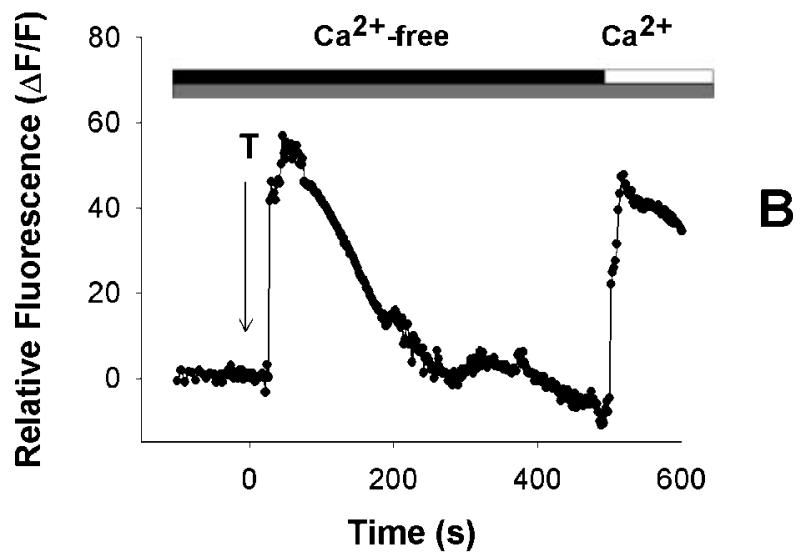

Figure $6 \mathrm{Ca}^{2+}$ responses in cytochalasin D-treated myotubes induced by testosterone. Myotubes were treated with cytochalasin for $1 \mathrm{~h}$ and then loaded with Fluo-3 AM to detect changes in intracellular $\mathrm{Ca}^{2+}$. (A) Cytochalasin D inhibited the $\mathrm{Ca}^{2+}$ oscillations, but not the sustained $\mathrm{Ca}^{2+}$ increase, induced by testosterone. (B) The cytoskeletal disruption in cytochalasin D-treated cells reduced the testosterone-induced CCE by $43 \%$ (note that the values of relative fluorescence in control conditions are in the range of 120-180 (Figs 3, 4 and 6)). The arrow indicates the time of addition of testosterone (T).

evidence that testosterone-induced $\mathrm{Ca}^{2+}$ responses in myotubes are complex, involving both intracellular and extracellular $\mathrm{Ca}^{2+}$ and can be divided into two components: $\mathrm{Ca}^{2+}$ release from $\mathrm{IP}_{3}$-sensitive stores (Estrada et al. 2000, 2003), which causes a rapid intracellular $\mathrm{Ca}^{2+}$ increase, and a CCE pathway through the plasma membrane, responsible for $\mathrm{Ca}^{2+}$ oscillations. Both these mechanisms are essential for the testosterone-induced $\mathrm{Ca}^{2+}$ response in myotubes.

In myotubes, the long-lasting $\mathrm{Ca}^{2+}$ rise of testosteroneinduced signaling is produced in $\mathrm{Ca}^{2+}$-containing as well as $\mathrm{Ca}^{2+}$-free medium, suggesting $\mathrm{Ca}^{2+}$ mobilization from internal stores, consistent with previous findings using inhibitors of $\mathrm{IP}_{3}$-mediated $\mathrm{Ca}^{2+}$ pathways such as $\mathrm{U} 73122$ and xestospongin B (Estrada et al. 2003). These results strongly suggest that stimulation of myotubes with testos- terone induces an intracellular $\mathrm{Ca}^{2+}$ increase through phosphoinositide signaling pathways. Intracellular $\mathrm{Ca}^{2+}$ oscillations are a common event in many different cell types. Different oscillatory patterns suggest different mechanisms of $\mathrm{Ca}^{2+}$ release and re-uptake as well as different signaling functions for intracellular $\mathrm{Ca}^{2+}$ (Dolmetsch et al. 1998, Li et al. 1998, Sneyd et al. 2004). In a high percentage of cells studied, the testosterone-induced $\mathrm{Ca}^{2+}$ rise was accompanied by $\mathrm{Ca}^{2+}$ oscillations, which may represent an important early step for the coordination of cell functions in skeletal muscle (Shtifman et al. 2004). In this study we show that the oscillatory pattern induced by testosterone exhibits a remarkably constant frequency $(49 \cdot 3 \pm 4 \cdot 4 \mathrm{mHz})$ corresponding to a periodicity of $\sim 20 \mathrm{~s}$, suggesting a highly regulated event. Interestingly, oscillations tend to decrease and fade 2 min after testosterone stimulation. This is consistent with the transient increase of $\mathrm{IP}_{3}$ seen after testosterone addition, which returns to basal values after 2 min (Estrada et al. 2003). Collet \& Ma (2004) have proposed a regulatory mechanism for CCE in skeletal muscle with an enhancement of SOC activity upon initial entry of extracellular $\mathrm{Ca}^{2+}$ followed by gradual and complete deactivation of the SOC channel function associated with the uptake of $\mathrm{Ca}^{2+}$ into the sarcoplasmic reticulum, which represents a graded deactivation process for CCE regulation, through $\mathrm{Ca}^{2+}$ storage, in times compatible with our results. Rapid frequency-dependent signals can be used by cells to activate simultaneously several cellular processes, thus allowing the same second messenger to be used for several different events. It has been reported that specific frequencies can activate specific genes (Dolmetsch et al. 1998, Li et al. 1998). $\mathrm{Ca}^{2+}$ oscillations have been shown in several biological systems. This study shows that a hormone, testosterone, can induce $\mathrm{Ca}^{2+}$ oscillations of a specific frequency. Testosteroneevoked $\mathrm{Ca}^{2+}$ oscillations only occurred in the presence of extracellular $\mathrm{Ca}^{2+}$. In several cell models, $\mathrm{Ca}^{2+}$ oscillations are reported to be initiated by $\mathrm{IP}_{3}$-induced release of $\mathrm{Ca}^{2+}$ from intracellular $\mathrm{Ca}^{2+}$ stores (Berridge \& Irvine 1989, Aizman et al. 2001). They are dependent, however, on $\mathrm{Ca}^{2+}$ influx through $\mathrm{Ca}^{2+}$ channels in the plasma membrane (Berridge \& Irvine 1989, Sneyd et al. 2004). $\mathrm{Ca}^{2+}$ oscillations induced by testosterone stimulation in myotubes thus appear to be similar to agonist-evoked $\mathrm{Ca}^{2+}$ oscillations in other excitable and non-excitable cells (Berridge \& Irvine 1989, Sergeeva et al. 2000, Aizman et al. 2001, Sneyd et al. 2004).

Depletion of intracellular $\mathrm{Ca}^{2+}$ stores by thapsigargin promoted activation of $\mathrm{Ca}^{2+}$ entry from the extracellular medium, suggesting the presence of a CCE pathway. Treatment of myotubes with thapsigargin blocked the $\mathrm{Ca}^{2+}$ signal induced by testosterone, indicating that the $\mathrm{Ca}^{2+}$ increase produced by this hormone involved intracellular $\mathrm{Ca}^{2+}$ stores sensitive to thapsigargin. Moreover, the fast $\mathrm{Ca}^{2+}$ entry after $\mathrm{Ca}^{2+}$ re-addition experiments in myotubes stimulated by testosterone or T-BSA in 
$\mathrm{Ca}^{2+}$-free medium indicates that testosterone activates a plasma membrane $\mathrm{Ca}^{2+}$ influx. The existence of CCE in skeletal muscle cells involving conformational coupling between the plasma membrane and either ryanodine receptors (Islam et al. 2002) or $\mathrm{IP}_{3} \mathrm{Rs}$ (Launikonis et al. 2003) has been postulated. We have previously shown that there is a caffeine-sensitive $\mathrm{Ca}^{2+}$ pool in these cells (Carrasco et al. 2003). In this study, however, ryanodine did not inhibit $\mathrm{Ca}^{2+}$ oscillations, suggesting that these effects are dependent on $\mathrm{IP}_{3} \mathrm{R}$ activation. All three types of $\mathrm{IP}_{3} \mathrm{R}$ have been found to be present in myotubes (C Cárdenas, J L Liberona, J Molgó, C Colasante, G A Mignery \& E Jaimovich, unpublished observations). Launikonis et al. (2003) have demonstrated in mechanically skinned skeletal muscle cells that $\mathrm{IP}_{3} \mathrm{R}$ mediates SOCs, and show evidence that the $\mathrm{IP}_{3} \mathrm{R}$ can act as a sarcoplasmic reticulum $\mathrm{Ca}^{2+}$ sensor necessary for CCE. It has further been suggested that $\mathrm{IP}_{3} \mathrm{R}$ could be physically coupled to integral membrane proteins, such as SOCs (Kiselyov et al. 1998, Ma et al. 2000, Launikonis et al. 2003) or $\mathrm{Na}^{+}, \mathrm{K}^{+}$-ATPase (Miyakawa-Naito et al. 2003). In adult skeletal muscle, CCE (through SOCs) was insensitive to nifedipine (Kurebayashi \& Ogawa 2001). In contrast, the role of voltage-gated $\mathrm{Ca}^{2+}$ channels in CCE was suggested in other cell types (Densmore et al. 1996, Aizman et al. 2001) and steroid-induced CCE has been postulated to occur through a transient receptor potential protein channel 3 (TRPC3)-like protein in rat osteoblasts (Baldi et al. 2003). Spontaneous $\mathrm{Ca}^{2+}$ oscillations in myotubes were described by Shtifman et al. (2004). These oscillations were inhibited by $\mathrm{Cd}^{3+} / \mathrm{La}^{3+}$, but also by nifedipine and so were attributed to $\mathrm{Ca}^{2+}$ entry through L-type $\mathrm{Ca}^{2+}$ channels. In our study, $\mathrm{Ca}^{2+}$ entry triggered by testosterone in myotubes was insensitive to the voltagedependent $\mathrm{Ca}^{2+}$ channel antagonist nifedipine, but was inhibited by $2-\mathrm{APB}$ and the non-specific $\mathrm{Ca}^{2+}$ channel blocker $\mathrm{La}^{3+}$, as identified by inhibition of $\mathrm{Ca}^{2+}$ entry in the $\mathrm{Ca}^{2+}$ re-addition protocols. At the concentration used, 2-APB has been shown to be a blocker of SOCs in several cell types including skeletal muscle (Bootman et al. 2002, Collet \& Ma 2004). Moreover, our results suggest that CCE participates in the generation of testosteroneinduced $\mathrm{Ca}^{2+}$ oscillations, because both $2-\mathrm{APB}$ and $\mathrm{La}^{3+}$ blocked this effect. 2-APB inhibited the testosteroneinduced, $\mathrm{IP}_{3}$-dependent $\mathrm{Ca}^{2+}$ signal by $43 \%$ whereas the CCE signal was inhibited by more than $66 \%$, indicating that CCE is more sensitive to this inhibitor than the $\mathrm{IP}_{3} \mathrm{R}$ pathway. Pre-incubation of myotubes with $\mathrm{La}^{3+}$ before the addition of testosterone, in $\mathrm{Ca}^{2+}$-free medium, did not cause a detectable inhibition of testosterone-induced $\mathrm{Ca}^{2+}$ release from intracellular stores, but completely inhibited $\mathrm{Ca}^{2+}$ oscillations.

Kiselyov et al. (1998) have suggested a physical interaction between $\mathrm{IP}_{3} \mathrm{R}$ and the plasma membrane that involves the actin cytoskeleton, and Mohler et al. (2004) have demonstrated a link between $\mathrm{IP}_{3} \mathrm{R}$ and ankyrin-B, a protein known to bind membrane proteins to the actin cytoskeleton, important in localization and stabilization of the receptor in neonatal cardiomyocytes. Cytochalasin D blocked intracellular $\mathrm{Ca}^{2+}$ oscillations, but not the testosterone-induced long-lasting rise in intracellular $\mathrm{Ca}^{2+}$. This drug only partly reduced the CCE seen upon re-introduction of $\mathrm{Ca}^{2+}$ to $\mathrm{Ca}^{2+}$-free external medium.

Early changes in myotubes by steroids could be directly related to activation of $\mathrm{Ca}^{2+}$-mediated events. The differential activation of a genomic or a non-genomic pathway could be important to the physiological relevance of testosterone in skeletal muscle, mediating such physiological responses as muscle hypertrophy. An early event in skeletal muscle hypertrophy is an increase in intracellular $\mathrm{Ca}^{2+}$ (Semsarian et al. 1999). Thus, for testosterone this mechanism is amenable to a two-step process as described for others steroid hormones (Wehling 1997), where both non-genomic and genomic effects occur sequentially. Thus, the pathways used by steroid hormones in different cell types could add another dimension of signal specificity. $\mathrm{Ca}^{2+}$ oscillations with frequency ranging from 10 to $50 \mathrm{mHz}$ (periodicities from 20 to $100 \mathrm{~s}$ ) have been described in various cell types upon different stimulation protocols (Li et al. 1998, Sneyd et al. 2004). Interestingly in cultured myotubes, spontaneous $\mathrm{Ca}^{2+}$ oscillations with a frequency of approximately $45 \mathrm{mHz}$ were described (Shtifman et al. 2004).

Taken together, these observations provide functional evidence for the existence of CCE induced by testosterone, which is necessary for the generation of $\mathrm{Ca}^{2+}$ oscillations in myotubes. The response is complex and is mediated by interplay between $\mathrm{IP}_{3}$-sensitive $\mathrm{Ca}^{2+}$ stores (Estrada et al. 2000, 2003) and $\mathrm{Ca}^{2+}$ influx through voltage-independent channels activated by store depletion.

\section{Funding}

This work was financed by: FONDECYT Grants 2000055 and 1030988 (M E), (P U) Vetenskapsrådet - the Swedish Research Council - and (C J G) Howard Hughes Medical Institute predoctoral fellowship. The authors declare that there is no conflict of interest that would prejudice the impartiality of this scientific work.

\section{References}

Aizman O, Uhlen P, Lal M, Brismar H \& Aperia A 2001 Ouabain, a steroid hormone that signals with slow calcium oscillations. PNAS 98 13420-13424

Baldi C, Vazquez G, Calvo JC \& Boland R 2003 TRPC3-like protein is involved in the capacitative cation entry induced by 1a,25-dihydroxy-vitamin $\mathrm{D}_{3}$ in ROS $17 / 2 \cdot 8$ osteoblastic cells. Journal of Cellular Biochemistry 90 197-205.

Benten WP, Lieberherr M, Stamm O, Wrehlke C, Guo Z \& Wunderlich F 1999 Testosterone signaling through internalizable surface receptors in androgen receptor-free macrophages. Molecular Biology of the Cell 10 3113-3123. 
Berridge MJ \& Irvine RF 1989 Inositol phosphates and cell signaling. Nature 341 197-205.

Bootman MD, Collins TJ, Mackenzie I, Roderick HI, Berridge MJ \& Peppiatt CM 2002 2-Aminoethoxydiphenyl borate (2-APB) is a reliable blocker of store-operated $\mathrm{Ca}^{2+}$ entry but an inconsistent inhibitor of $\mathrm{InsP}_{3}$-induced $\mathrm{Ca}^{2+}$ release. FASEB Journal 16 $1145-1150$

Carrasco MA, Riveros N, Ríos J, Müller M, Torres F, Pineda J, Lantadilla S \& Jaimovich E 2003 Depolarization induced slow calcium transients activate early genes in skeletal muscle cells. American Journal of Physiology - Cell Physiology 284 C1438-C1447.

Cato AC \& Peterziel H 1998 The androgen receptor as mediator of gene expression and signal transduction pathways. Trends in Endocrinology and Metabolism 4 150-154.

Collet C \& Ma J 2004 Calcium-dependent facilitation and graded deactivation of store-operated calcium entry in fetal skeletal muscle. Biophysical Journal 87 268-275.

Densmore JJ, Haverstick DM, Szabo G \& Gray LS 1996 A voltage-operable current is involved in $\mathrm{Ca}^{2+}$ entry in human lymphocytes whereas $\mathrm{I}_{\mathrm{CRAC}}$ has no apparent role. American Journal of Physiology - Cell Physiology 271 C1494-C1503.

Dolmetsch RE, Xu K \& Lewis RS 1998 Calcium oscillations increase the efficiency and specificity of gene expression. Nature 392 933-936.

Estrada M, Liberona JL, Miranda M \& Jaimovich E 2000 Aldosteroneand testosterone-mediated intracellular calcium response in skeletal muscle cell cultures. American Journal of Physiology - Endocrinology and Metabolism 279 E132-E139.

Estrada M, Espinosa A, Muller M \& Jaimovich E 2003 Testosterone stimulates intracellular calcium release and mitogen-activated protein kinases via a $\mathrm{G}$ protein-coupled receptor in skeletal muscle cells. Endocrinology 144 3586-3597.

Islam MN, Narayanan B \& Ochs RS 2002 A mechanism for both capacitative $\mathrm{Ca}^{2+}$ entry and excitation-contraction coupled $\mathrm{Ca}^{2+}$ release by the sarcoplasmic reticulum of skeletal muscle cells. Experimental Biology and Medicine 227 425-431.

Jaimovich E, Liberona JL, Reyes R \& Powell JA 2000 Nuclear $\mathrm{IP}_{3}$ receptors, $\mathrm{IP}_{3}$ transients and nucleus-associated calcium signals in cultured skeletal muscle. American Journal of Physiology - Cell Physiology 278 C998-C1010.

Kiselyov K, Xu X, Mozhayeva G, Kuo T, Pessah I, Mignery G, Zhu X, Birnbaumer L \& Muallem S 1998 Functional interaction between $\mathrm{InsP}_{3}$ receptors and store-operated Htrp3 channels. Nature 396 478-482.

Kurebayashi N \& Ogawa Y 2001 Depletion of $\mathrm{Ca}^{2+}$ in the sarcoplasmic reticulum stimulates $\mathrm{Ca}^{2+}$ entry into mouse skeletal muscle fibres. Journal of Physiology 533 185-199.

Launikonis BS, Barnes M \& Stephenson DG 2003 Identification of the coupling between skeletal muscle store-operated $\mathrm{Ca}^{2+}$ entry and the inositol trisphosphate receptor. PNAS 100 2941-2944.

Lee WJ, Thompson RW, McClung JM \& Carson JA 2003 Regulation of androgen receptor expression at the onset of functional overload in rat plantaris muscle. American Journal of Physiology - Regulative, Integrative and Comparative Physiology 285 R1076-R1085.

Li W-h, Llopis J, Whitney M, Zlokarnik G \& Tsien RY 1998 Cell-permeant caged $\mathrm{Ins}_{3}$ ester shows that $\mathrm{Ca}^{2+}$ spike frequency can optimize gene expression. Nature 392 936-941.

Lieberherr M \& Grosse B 1994 Androgens increase intracellular calcium concentration and inositol 1,4,5-trisphosphate and diacylglycerol formation via a pertussis toxin-sensitive G-protein. Journal of Biological Chemistry 269 7217-7223.
Ma HT, Patterson RL, van Rossum DB, Birnbaumer L, Mikoshiba K \& Gill DL 2000 Requirement of the inositol trisphosphate receptor for activation of store-operated $\mathrm{Ca}^{2+}$ channels. Science 287 $1647-1651$.

Minta A, Kao JPY \& Tsien RY 1986 Fluorescent indicators for cytosolic calcium based on rhodamine and fluorescent chromophores. Journal of Biological Chemistry 264 8171-8178.

Miyakawa-Naito A, Uhlen P, Lal M, Aizman O, Mikoshiba K, Brismar H, Zelenin S \& Aperia A 2003 Cell signaling microdomain with $\mathrm{Na}, \mathrm{K}$-ATPase and inositol 1,4,5-trisphosphate receptor generates calcium oscillations. Journal of Biological Chemistry 278 50355-50361.

Mohler PJ, Davis JQ, Davis LH, Hoffman JA, Michaely P \& Bennett V 2004 Inositol 1,4,5-trisphosphate receptor localization and stability in neonatal cardiomyocytes requires interaction with ankyrin-B. Journal of Biological Chemistry 279 12980-12987.

Mooradian AD, Morley JE \& Korenman SG 1987 Biological actions of androgens. Endocrine Reviews 8 1-28.

Pedrosa-Ribeiro CM, Reece J \& Putney JW Jr 1997 Role of the cytoskeleton in calcium signaling in NIH 3 T3 cells. Journal of Biological Chemistry 272 26555-26561.

Powell JA, Carrasco MA, Adams D, Drouet B, Rios J, Müller M, Estrada M \& Jaimovich E $2001 \mathrm{IP}_{3}$ receptor function and localization in myotubes: an unexplored $\mathrm{Ca}^{2+}$ signaling pathway in skeletal muscle. Journal of Cell Science 114 3673-3683.

Powers ML \& Florini JR 1975 A direct effect of testosterone on muscle cells in tissue culture. Endocrinology 97 1043-1047.

Putney JW Jr, Broad LM, Braun FJ, Lievremont JP \& Bird GS 2001 Mechanisms of capacitative calcium entry. Journal of Cell Science 114 2223-2229.

Semsarian C, Wu M, Ju Y, Marciniec T, Yeoh T, Allen D, Harvey R \& Graham RM 1999 Skeletal muscle hypertrophy is mediated by a $\mathrm{Ca}^{2+}$-dependent calcineurin signalling pathway. Nature $\mathbf{4 0 0}$ $576-580$.

Sergeeva M, Ubl JJ \& Reiser G 2000 Disruption of actin cytoskeleton in cultured rat astrocytes suppresses ATP- and bradykinin-induced $\left[\mathrm{Ca}^{2+}\right]_{\mathrm{i}}$ oscillations by reducing the coupling efficiency between $\mathrm{Ca}^{2+}$ release, capacitative $\mathrm{Ca}^{2+}$ entry, and store refilling. Neuroscience 97 765-769.

Shtifman A, Paolini C, Lopez JR, Allen PD \& Protasi F $2004 \mathrm{Ca}^{2+}$ influx through $\alpha_{1 \text { S }}$ DHPR may play a role in regulating $\mathrm{Ca}^{2+}$ release from RyR1 in skeletal muscle. American Journal of Physiology - Cell Physiology 286 C73-C78.

Sneyd J, Tsaneva-Atanasova K, Yule DI, Thompson JL \& Shuttleworth TJ 2004 Control of calcium oscillations by membrane fluxes. PNAS 101 1392-1396.

Venkatachalam K, Van Rossum DB, Patterson RL, Ma HT \& Gill DL 2002 The cellular and molecular basis of store-operated calcium entry. Nature Cell Biology 4 E263-E272.

Wehling M 1997 Specific, nongenomic actions of steroid hormones. Annual Review of Physiology 59 365-393.

Zagar Y, Chaumaz G \& Lieberherr M 2004 Signaling cross-talk from $\mathrm{G}_{4}$ subunit to Elk-1 in the rapid action of androgens. Journal of Biological Chemistry 279 2403-2413.

Received 6 October 2004

Accepted 2 November 2004

Made available online as an Accepted Preprint 